\title{
Characteristic Wettability of SiC by Liquid Pure $\mathrm{Cu}$
}

\author{
By Kiyoshi Nogi* and Kazumi Ogino*
}

\begin{abstract}
The wettabilities of $\alpha$-SiC, hot pressed $\mathrm{SiC}$, and reaction bonded $\mathrm{SiC}$ by liquid $\mathrm{Cu}$ were investigated using the sessile drop method under various experimental conditions.

The main results obtained are summarized as follows:

(1) The contact angle of liquid $\mathrm{Cu}$ on $\mathrm{SiC}$ depended on $\mathrm{SiC}$ used.

(2) The characteristic wetting was observed in the liquid pure $\mathrm{Cu} / \alpha$-SiC system, which had a hexagonal wetted area.

(3) The appearance of hexagonal wetting depended on temperature and pressure: at lower temperatures and pressures, hexagonal wetting was observed, and at relatively higher temperatures and pressures, normal wetting was observed.

(4) The mechanism of the formation of hexagonal wetting is closely related to that of hexagonal etch pits by fused $\mathrm{KOH}$ solution.
\end{abstract}

$$
\text { (Received May 24, 1988) }
$$

Keywords: wettability, silicon carbide, contact angle, liquid copper, composites

\section{Introduction}

Ceramics are becoming increasingly important as engineering materials. They are generally stronger, more refractory, less thermally expansive and less reactive than metals. However, as the ceramics are weak in thermal shock, it is important to use them with metals, i.e. metal-ceramic joining and composites.

As the wettability of ceramics by liquid metals gives us important information on the production of composite materials and to metal-ceramics joinings, many reports concerning the wettability have already been published. However, the results are not in coincidence, because the wetting properties such as the contact angle of liquid metal on ceramic and the work of adhesion between liquid metal and ceramic are easily affected by the presence of small amounts of impurities both in the metal and ceramic employed, and also by atmosphere.

In this work, the wettability of a reaction bonded $\mathrm{SiC}$, a hot pressed $\mathrm{SiC}$, and a single crystal of $\alpha$-SiC by liquid pure $\mathrm{Cu}$ was exam-

* Department of Materials Science and Processing, Faculty of Engineering, Osaka University, 2-1 Yamadaoka, Suita, Osaka 565, Japan. ined using the sessile drop method. The wettability was evaluated by measuring the contact angle of liquid $\mathrm{Cu}$ on $\mathrm{SiC}$.

\section{Experimental}

\section{Materials}

Electrolyzed $\mathrm{Cu}$ was vacuum-melted in a high purity graphite crucible to remove oxygen contained. After treatment, no oxygen was detected in the sample by the inert gas carrier method.

The SiC samples used were a reaction bonded $\mathrm{SiC}$ which contained $10 \% \mathrm{Si}$ as a form of metallic silicon, a hot pressed $\mathrm{SiC}$, and a single crystal of $\alpha$-SiC. Measurements for $\alpha$-SiC were carried out on the plane of (0001).

The reaction bonded $\mathrm{SiC}$ obtained from Nippon Kagaku Togyo Co. Ltd. included 10 mass \% of metallic Si.

The hot pressed $\mathrm{SiC}$ was made from $\mathrm{SiC}$ powder whose mean particle size was $0.05 \mu \mathrm{m}$ and impurities were as follows; 0.01 mass $\%$ of $\mathrm{C}, 0.03$ mass $\%$ of $\mathrm{Al}, 0.03$ mass $\%$ of $\mathrm{Fe}$ and 0.4 mass $\%$ of $\mathrm{SiO}_{2}$. The hot pressed $\mathrm{SiC}$ substrates were prepared under a pressure of c.a. $550 \mathrm{~kg} / \mathrm{cm}^{2}$ at temperatures of $2223 \mathrm{~K}$ or above. As graphite dies were employed, the metallic $\mathrm{Si}$ and $\mathrm{SiO}_{2}$ existing on the surface of a 
substrate could be expected to change into $\mathrm{SiC}$.

The single crystal of $\alpha$-SiC contained 0.02 mass $\%$ of $\mathrm{Fe}, 0.02$ mass $\%$ of $\mathrm{Al}$ and 0.01 mass \% of C.

The SiC powder and the single crystal of $\alpha$ $\mathrm{SiC}$ were purchased from Pacific Rundum Co., Ltd.

Porosities of the reaction bonded $\mathrm{SiC}$ and the single crystal of $\alpha$-SiC were zero, and that of the hot pressed $\mathrm{SiC}$ was c.a. $5 \%$.

Several experiments were carried out using $\mathrm{SiO}_{2}$ as a substrate to clarify the effect of the oxide film which would be expected to exist on $\mathrm{SiC}$.

\section{Apparatus and procedures}

The furnace used is shown in Fig. 1. Measurements were carried out in a reduced

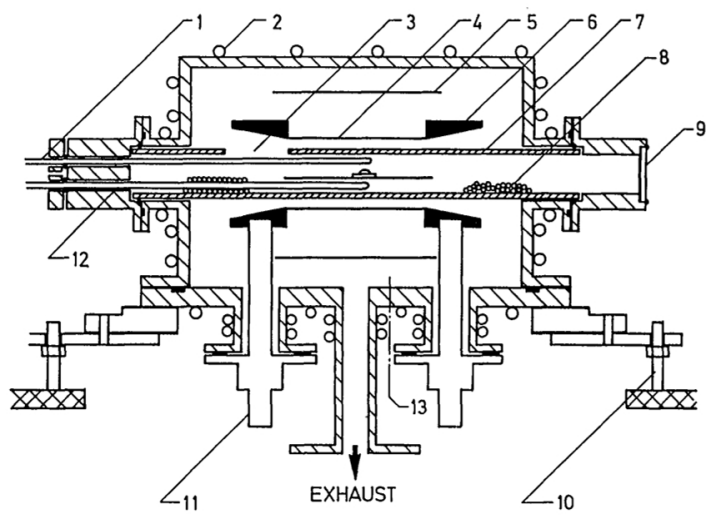

Fig. 1 Apparatus for measurement. 1. Metal dropping device, 2. Water cooling pipe, 3. Exhaust hole, 4. Carbon net heater, 5. Mo radiation shield, 6. Graphite ring, 7. Alumina tube, 8. Titanium getter, 9. Observation window, 10. Levelling screw, 11. Water cooled $\mathrm{Cu}$ electrode, 12. Thermocouple, 13. Ionization Vacuum gauge. pressure (c.a. $10^{-3} \mathrm{~Pa}$ ). As the heating element was a graphite net, oxygen in an atmosphere could be reduced by eq. (1).

$$
\mathrm{C}+\frac{1}{2} \mathrm{O}_{2}=\mathrm{CO}
$$

Oxygen in an atmosphere can be removed by the reaction which is expressed by eq. (1) and also sponge $\mathrm{Ti}$ which is set in the furnace.

Measurements were made mostly under a reduced pressure.

First, a SiC substrate was set horizontally in the furnace and a $\mathrm{Cu}$ (c.a. $1.5 \mathrm{~g}$ ) sample in the metal dropping assembly. Then the furnace was evacuated. Pressure should be maintained at $10^{-3} \mathrm{~Pa}$ or lower at room temperature. After attaining a pre-set temperature, liquid $\mathrm{Cu}$ was dropped onto the SiC. Photographs of liquid $\mathrm{Cu}$ drop were taken every several hundreds seconds. Contact angles were determined by the tables of Bashforth and Adams ${ }^{(1)}$.

\section{Results and Discussion}

Typical examples of shapes of liquid $\mathrm{Cu}$ drop on various $\mathrm{SiC}$ are shown in Figs. 2-4. As can be seen from Figs. 2-4, the shape of a liquid $\mathrm{Cu}$ drop on a single crystal of $\alpha-\mathrm{SiC}$ is absolutely different from that on a reaction bonded $\mathrm{SiC}$ or on a hot pressed SiC. A liquid drop on a substrate must have a smooth surface as in Figs. 2 and 3. Many liquid metals / ceramics systems have been examined by the authors $^{(2)-(11)}$ and no system like the liquid pure $\mathrm{Cu} / \alpha$-SiC one has been observed before except for the liquid pure $\mathrm{Fe} / \mathrm{Al}_{2} \mathrm{O}_{3}$ system which was attempted in reduced pressure ${ }^{(11)}$. In the liquid pure $\mathrm{Fe} / \mathrm{Al}_{2} \mathrm{O}_{3}$ system, the $\mathrm{Al}$ rich layer was

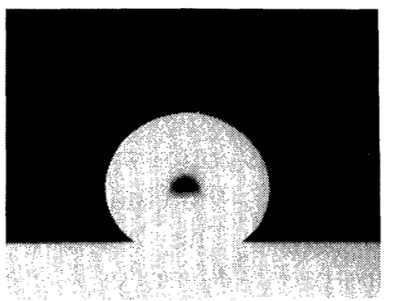

O ks

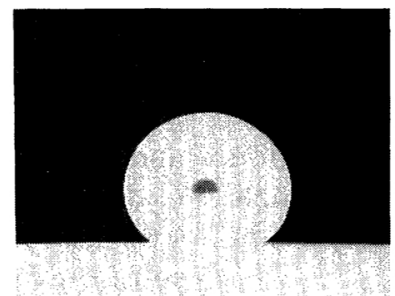

$0.9 \mathrm{ks}$

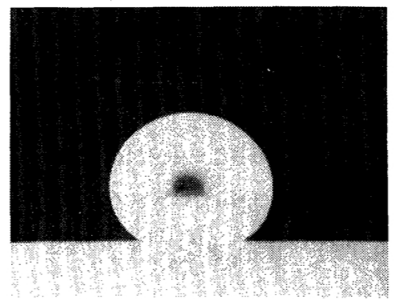

$1.8 \mathrm{ks}$

Fig. 2 Change in shape of liquid pure $\mathrm{Cu}$ on hot pressed $\mathrm{SiC}$ with time. 


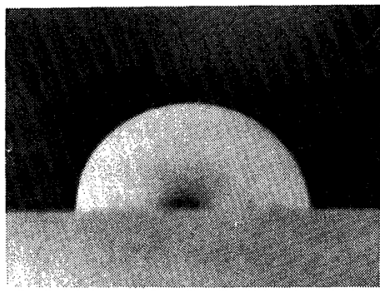

$0 \mathrm{ks}$

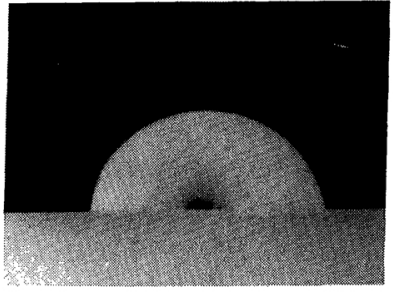

$0.9 \mathrm{ks}$

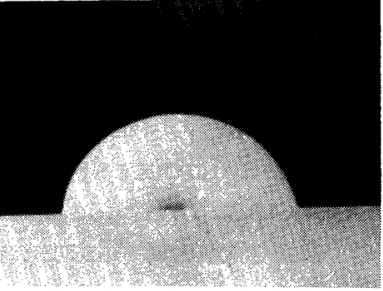

$1.8 \mathrm{ks}$

Fig. 3 Change in shape of liquid pure $\mathrm{Cu}$ on reaction bonded $\mathrm{SiC}$ with time.

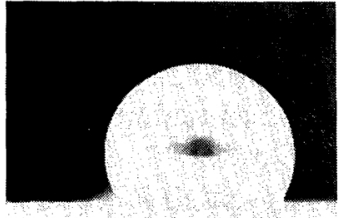

$0 \mathrm{ks}$

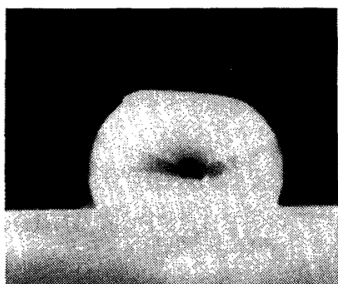

$0.3 \mathrm{ks}$

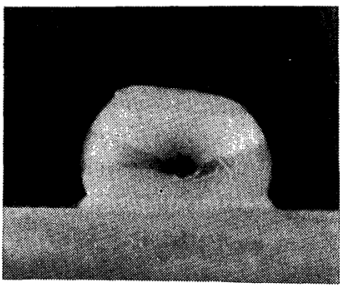

$0.6 \mathrm{ks}$

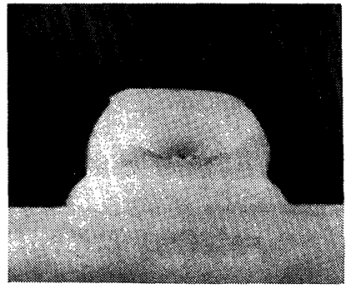

$1.2 \mathrm{ks}$

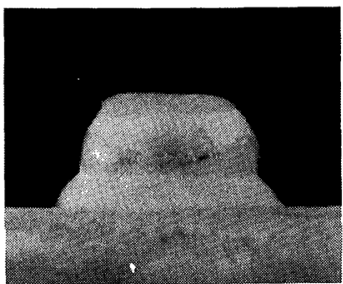

$1.5 \mathrm{ks}$

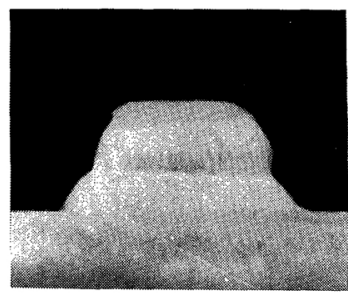

$1.8 \mathrm{ks}$

Fig. 4 Change in shape of liquid pure $\mathrm{Cu}$ on single crystal of $\alpha$-SiC with time.

detected by EPMA analysis at the surface of a liquid $\mathrm{Fe}$ drop which was supposed to be an oxide layer. The EPMA analysis also revealed that the Si content at the interface between a solidified $\mathrm{Cu}$ drop and a single crystal of $\mathrm{SiC}$ was higher than that in the bulk of solidified drop, while no difference in the Si content between the bulk and the interface was observed

when the reaction bonded $\mathrm{SiC}$ and the hot pressed $\mathrm{SiC}$ were used.

Unfortunately, as the phase-diagram of the $\mathrm{Cu}-\mathrm{Si}-\mathrm{C}$ system has not been investigated yet, it is difficult to evaluate solubilities of $\mathrm{Si}$ and $\mathrm{C}$ in liquid $\mathrm{Cu}$ at the experimental temperature. However, Bates et al. ${ }^{(12)}$ found decomposition of $\mathrm{SiC}$ into liquid $\mathrm{Cu}$ and Naidich ${ }^{(13)}$ found an intermediate layer between liquid $\mathrm{Cu}$ and $\mathrm{SiC}$. These results do not conflict with the result obtained in this work, although a quantitative analysis of $\mathrm{C}$ in solidified $\mathrm{Cu}$ samples could not be carried out, because the $\mathrm{Cu}$ drop was too small and too hard to take off from the $\alpha$ $\mathrm{SiC}$ to be carried out a carbon analysis.

Contact angles of liquid $\mathrm{Cu}$ and $\mathrm{Si}$ content in liquid $\mathrm{Cu}$ on various $\mathrm{SiC}$ at $1393 \mathrm{~K}$ are summarized in Table 1. Considerable difference in contact angles are observed. The liquid $\mathrm{Cu} /$ hot pressed $\mathrm{SiC}$ system is a non-wetting one, while Liquid $\mathrm{Cu} /$ reaction bonded $\mathrm{SiC}$ system is a wetting one. This difference may be considered to be mainly caused by the dissolution of $\mathrm{Si}$ contained in a reaction bonded $\mathrm{SiC}$ which is shown in Table 1.

Table 1 Contact angle of liquid $\mathrm{Cu}$ on $\mathrm{SiC}$ at $1393 \mathrm{~K}$.

\begin{tabular}{ccc}
\hline \hline SiC & Contact angle & $\begin{array}{c}\text { Si content } \\
\text { (at\%) }\end{array}$ \\
\hline Hot pressed & $135.8^{\circ}$ & 0.5 \\
& $132.5^{\circ}$ & 0.8 \\
& $133.0^{\circ}$ & 0.7 \\
\hline Reaction bonded & $83.3^{\circ}$ & 18.0 \\
& $81.6^{\circ}$ & 18.0 \\
& $79.6^{\circ}$ & 19.2 \\
\hline Single crystal & not determined & $4.3^{*}$ \\
\hline
\end{tabular}

* Si contents depended on analyzed position 
The contact angle on reaction bonded $\mathrm{SiC}$ obtained here, $81.5 \pm 2^{\circ}$, is considerably lower than $106 \pm 2^{\circ(14)}$ at $1408 \mathrm{~K}$.

The difference in contact angle might be attributed to the difference in the atmosphere, more precisely the difference in oxygen partial pressure of atmosphere. The measurements in the previous work $^{(14)}$ were not carried out under a reduced pressure but in $\mathrm{Ar}$ atmosphere. The oxygen partial pressure in the previous work ${ }^{(14)}$ was found to be $10^{-9} \mathrm{~Pa}$ by an EMF measurement. On the other hand, the oxygen partial pressure in this work could not be determined precisely, since it was too low for the EMF measurement. However, it is possible to say that the oxygen partial pressure in this work was lower than $10^{-14} \mathrm{~Pa}$.

The $\mathrm{Si}$ content in a liquid $\mathrm{Cu}$ was 4.3 at\% and 18.0-19.2 at\%, respectively, in the previous work and in this work. This difference in Si content might be caused by an oxidation of some of $\mathrm{Si}$ in the reaction bonded $\mathrm{SiC}$ in the previous work.

The contact angle of liquid $\mathrm{Cu}$ on $\mathrm{SiO}_{2}$ was measured at $1393 \mathrm{~K}$. The value, $127^{\circ}$, for the liquid $\mathrm{Cu} / \mathrm{SiO}_{2}$ system is comparable to the values of $106^{\circ}$ and $81.5^{\circ}$ for the liquid $\mathrm{Cu} / \mathrm{SiC}$ system. The value, $106^{\circ}$, obtained in the previous work is close to that for the liquid $\mathrm{Cu} / \mathrm{SiC}$ system. This can support that the oxidation of Si occurred in the previous work ${ }^{(14)}$.

The contact angle of liquid $\mathrm{Cu}$ on a single crystal of $\alpha$-SiC could not be determined since a solid-like interface layer was formed at the interface between liquid $\mathrm{Cu}$ and $\alpha$-SiC (see Fig. 4). Metallic Si scarcely exists in both the hot pressed $\mathrm{SiC}$ and $\alpha-\mathrm{SiC}$, but the $\mathrm{Si}$ contents in liquid $\mathrm{Cu}$ on the hot pressed $\mathrm{SiC}$ and $\alpha$-SiC given in Table 1 show a big difference. This might be attributed to the difference in reactivity between the hot pressed $\mathrm{SiC}$ and the $\alpha$-SiC, which will be discussed later.

The shape of the solidified $\mathrm{Cu}$ drop on $\alpha$-SiC is shown in Fig. 5. The outside surface of the $\mathrm{Cu}$ drop is the hexagonal shape whose each rim is exactly parallel to that of $\alpha$-SiC. It can be concluded that the appearance of a $\mathrm{Cu}$ drop on the (0001) plane of $\alpha-\mathrm{SiC}$ is absolutely controlled by the nature of the surface of $\alpha-\mathrm{SiC}$.

Results obtained for liquid $\mathrm{Cu}$ on the $\alpha$-SiC system under various experimental conditions are summarized in Table 2. Hexagonal wetting was clearly observed at relatively lower temperatures and lower pressures, while no hexagonal wetting was observed at higher temperatures and higher pressures.

Figures 6 and 7 show etch pits on the (0001) plane of $\alpha-\mathrm{SiC}$ which resulted from fused $\mathrm{KOH}$ treatment at $950 \mathrm{~K}$. It is obvious from Fig. 6 that the hexagonal etch pits were formed on the surface of $\alpha$-SiC. Each rim was parallel to an edge of $\alpha$-SiC. Although the sizes of hexagons obtained by fused $\mathrm{KOH}$ treatment differ from those obtained by liquid $\mathrm{Cu}$, their rims also run parallel to those of $\alpha$-SiC.

The process of the formation and growth of etch pits observed is shown in Fig. 7. The formation of etch pits was observed after $0.6 \mathrm{ks}$ of fused $\mathrm{KOH}$ treatment but the shapes were not clear. After $1.2 \mathrm{ks}$ of the treatment, the shapes became clear and an incorporation of etch pits began. Finally, the incorporation of the left side and right side groups was observed.

The $\alpha$-SiC surface after removing $\mathrm{Cu}$ by $\mathrm{HNO}_{3}$ solution was observed by SEM as shown in Fig. 8. It may be seen from Fig. 8-a that many small hexagons were formed on the (0001) plane of a surface of $\alpha$-SiC. Figure 8-b shows their growth and incorporation. On the other hand, on the sample which had not shown the hexagonal wetting, no hexagons could be observed on the (0001) plane after removing $\mathrm{Cu}$ but a chemical attack of the surface by liquid $\mathrm{Cu}$ was observed.

It can be considered that the characteristic wetting observed in the liquid $\mathrm{Cu} / \alpha$-SiC system is caused by the difference in the dissolution rate of $\mathrm{SiC}$ into liquid $\mathrm{Cu}$ which depends on the orientation of surface of $\alpha-\mathrm{SiC}$.

Many reports on the wettability of single crystals of ceramics such as oxides and carbides have been published, but none of the characteristic wetting observed in this work has been reported.

The mechanism of hexagonal wetting may be considered as follows:

(1) The formation and growth of etch pits resulting from the difference in the dissolution rate of $\alpha$-SiC into liquid $\mathrm{Cu}$ which depends on the surface orientation of $\alpha-\mathrm{SiC}$. 


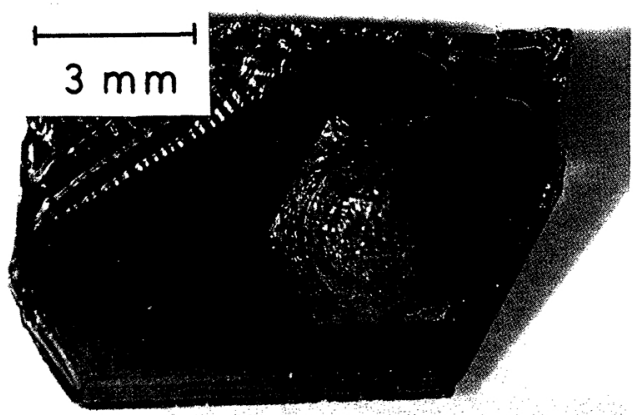

Table 2 Experimental results.

\begin{tabular}{cccccc}
\hline \hline $\begin{array}{c}\text { Temp } \\
(\mathrm{K})\end{array}$ & $\begin{array}{c}\text { Atmos- } \\
\text { phere } \\
(\mathrm{Pa})\end{array}$ & $\begin{array}{c}\text { Hex- } \\
\text { agonal } \\
\text { wetting }\end{array}$ & $\begin{array}{c}\text { Temp } \\
(\mathrm{K})\end{array}$ & $\begin{array}{c}\text { Atmos- } \\
\text { phere } \\
(\mathrm{Pa})\end{array}$ & $\begin{array}{c}\text { Hex- } \\
\text { agonal } \\
\text { wetting }\end{array}$ \\
\hline 1371 & $10^{-3}$ & 0 & 1440 & $10^{-3}$ & 0 \\
1393 & $10^{-3}$ & 0 & 1473 & $10^{-3}$ & $\times$ \\
1393 & $10^{-2}$ & 0 & 1393 & 10 & 0 \\
1393 & $10^{-1}$ & $\mathrm{O}$ & 1393 & $10^{5} \mathrm{Ar}$ & $\times$ \\
\hline \hline
\end{tabular}

(O): Clearly observed, 0 : Observed, $x$ : Not observed

Fig. 5 Appearance of solidified $\mathrm{Cu}$ drop on $\alpha$-SiC.
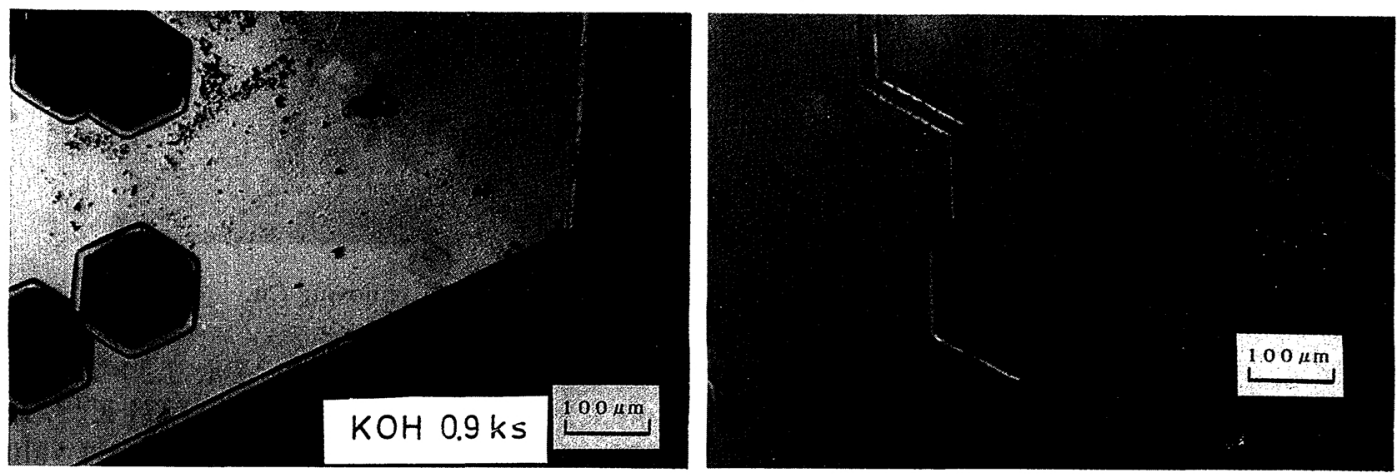

Fig. 6 Etch pits resulting from fused $\mathrm{KOH}$.
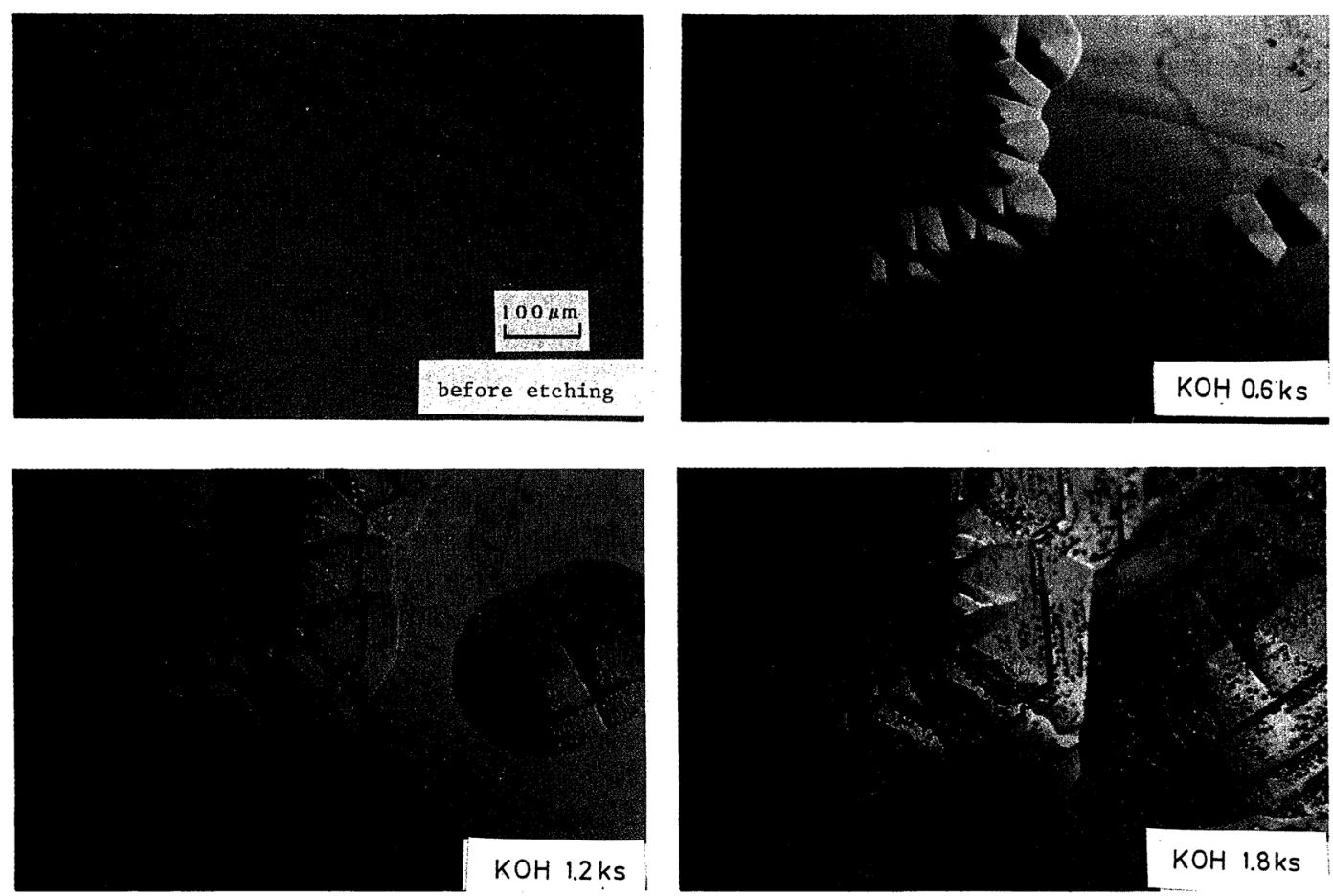

Fig. 7. Etch pits resulting from fused $\mathrm{KOH}$. 

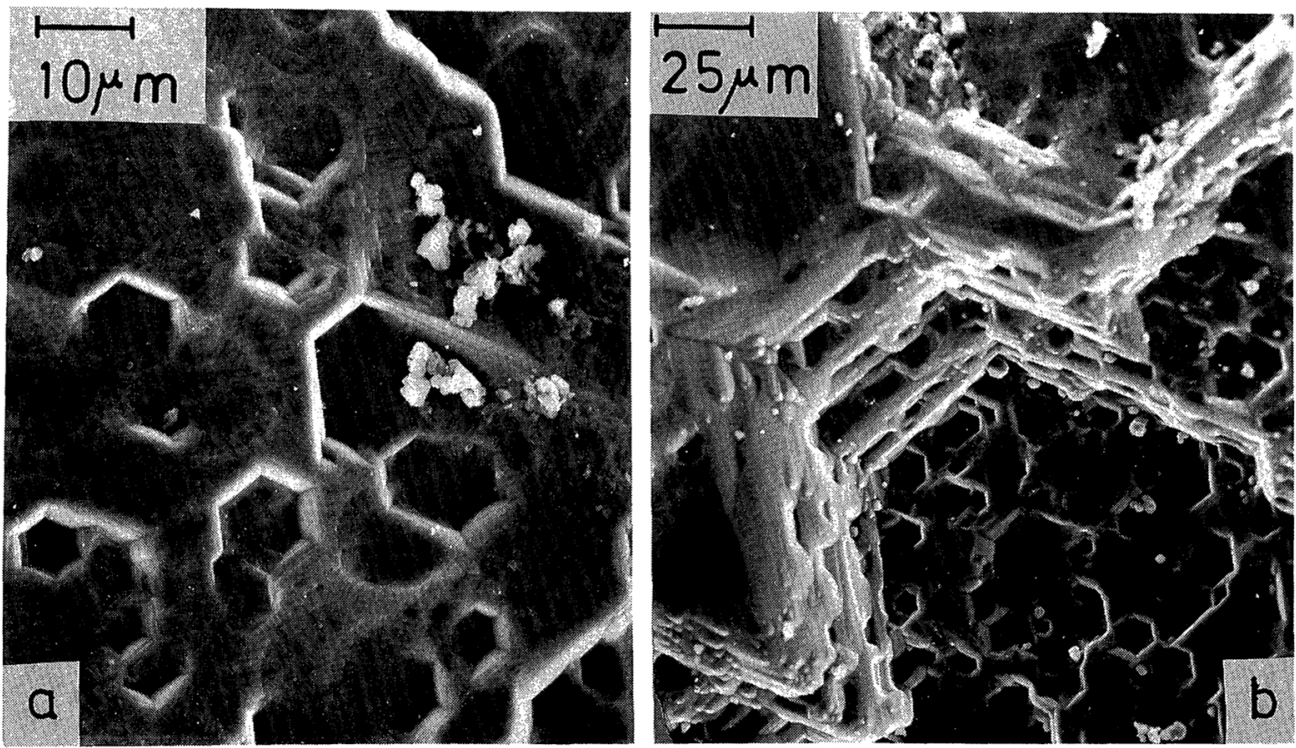

Fig. 8 SEM observation of the (0001) plane of $\alpha$-SiC after removing $\mathrm{Cu}$.

(2) Supersaturation of $\mathrm{Si}$ and $\mathrm{C}$ in liquid $\mathrm{Cu}$ attributed to the evaporation of $\mathrm{Cu}$ under reduced pressure.

(3) Precipitation of supersaturated $\mathrm{Si}$ and $\mathrm{C}$ at the liquid $\mathrm{Cu} / \mathrm{SiC}$ interface.

In the case of stage (1), it is reasonable to consider that the same phenomena as $\mathrm{KOH}$ treatment occurred in the case of the liquid $\mathrm{Cu} / \alpha$-SiC comparing Fig. 8 with Figs. 6 and 7 .

Berg $^{(15)}$ found a triangular and a hexagonal wetting of liquid In on the (111) plane of Ge, while Goldstein ${ }^{(16)}$ found that the dissolution rate of $\mathrm{Ge}$ into liquid In depended on the crystal plane of $\mathrm{Ge}$, and the difference in the dissolution rate was dominant at lower temperature. If the difference in the dissolution rate of $\alpha$-SiC into liquid $\mathrm{Cu}$ was also dominant at lower temperature, the results in Table 2 are understandable, i.e. the lower the temperature, the clearer becomes the shape of hexagon.

In stage (2) and (3), as it was not possible to determine a loss in weight during the experiment because of vigorous reaction between liquid $\mathrm{Cu}$ and $\alpha$-SiC, the loss was expected by a thermodynamic calculation. The vapor pressure of pure $\mathrm{Cu}, \mathrm{Si}$ and $\mathrm{C}$ was compared at experimental temperature, since no data were available for activities of $\mathrm{Cu}, \mathrm{Si}$ and $\mathrm{C}$ in $\mathrm{Cu}-$ $\mathrm{Si}-\mathrm{C}$ ternary system. The vapor pressures of
$\mathrm{Cu}, \mathrm{Si}$ and $\mathrm{C}$ are $1.3 \times 10^{-2} \mathrm{~Pa}, 3.3 \times 10^{-5} \mathrm{~Pa}$, and $7.5 \times 10^{-15}$, respectively, at $1371 \mathrm{~K}^{(17)}$. It is evident from the comparison of these values that as the vapor pressure of $\mathrm{Cu}$ is higher than those of $\mathrm{Si}$ and $\mathrm{C}$, it is possible for stage (2) to occur.

Two possibilities can be considered for stage (3).

(a) An epitaxial growth of solid from supersaturated liquid on (0001) plane of $\alpha$-SiC.

(b) The precipitation of solid from supersaturated liquid whose shape is regulated by the shape of the hollow formed by etching with liquid $\mathrm{Cu}$.

The Laue method was applied to the sample which had been cut parallel to the interface layer to investigate the possibility of epitaxial growth. The diffraction pattern did not reveal that the structure at the vicinity of the interface corresponded to the structure of SiC. Accordingly, this possibility can be denied, although a slight possibility remains.

It may be reasonable to conclude from the similarity between the hexagons resulting from fused $\mathrm{KOH}$ and the hexagons observed in Fig. 8 that (b) is the mechanism of the hexagonal wetting.

Although the characteristic wetting found in the present work has not been reported yet on 
liquid metals/single crystal of ceramics systems, it has been clarified that the wettability of a single crystal of ceramics by liquid metal can be affected by a crystal structure of $\alpha-\mathrm{SiC}$.

\section{Conclusion}

The wettability of $\mathrm{SiC}$ by liquid $\mathrm{Cu}$ was investigated using the sessile drop method.

(1) The contact angle of liquid $\mathrm{Cu}$ on $\mathrm{SiC}$ depended on $\mathrm{SiC}$ used.

(2) Hexagonal wetting was observed in liquid $\mathrm{Cu} / \alpha$-SiC system.

(3) The mechanism of the formation of hexagonal wetting closely relates to that of hexagonal etch pits by fused $\mathrm{KOH}$ solution.

(4) Hexagonal wetting depended on temperature and pressure.

\section{Acknowledgments}

The authors are indebted to Mr. K. Ikeda and Mr. T. Ueda for their devoted experimental work and to the Ministry of Education, Science and Culture, Japan for its financial support in the form of a Grant-in-Aid for Scientific Research.

\section{REFERENCES}

(1) F. Bashforth and J. C. Adams: An Attempt to Test the Theories of Capillary Action, Cambridge Univ.
Press, (1883).

(2) K. Ogino, A. Adachi and K. Nogi: Tetsu-to-Hagané, 59 (1973), 1237.

(3) K. Ogino, K. Nogi and Y. Koshida: Tetsu-to-Hagané, 59 (1973), 1380.

(4) K. Ogino, K. Nogi and O. Yamase: Tetsu-to-Hagané, 66 (1980), 179.

(5) K. Ogino and H. Taimatsu: J. Japan Inst. Metals, 43 (1979), 871.

(6) K. Ogino, H. Taimatsu and F. Nakatani: J. Japan Inst. Metals, 46 (1982), 957.

(7) K. Ogino, H. Taimatsu and F. Nakatani: J. Japan Inst. Metals, 46 (1982), 1049.

(8) H. Taimatsu, N. Abe, F. Nakatani and K. Ogino: J. Japan Inst. Metals, 49 (1985), 523.

(9) K. Nogi and K. Ogino: will be published in J. Japan Inst. Metals.

(10) K. Nogi, K. Oishi and K. Ogino: J. Japan Inst. Metals, 52 (1988), 72.

(11) K. Nogi, T. Kurachi and K. Ogino: Tetsu-to-Hagané, 74 (1988), 648.

(12) H. E. Bates, B. Wald and M. Weinstein: Advanced Fibrous Composite, SAMPE, 10 (1966), p. E41.

(13) Yu. V. Naidich: Prog. Surf. Membr. Sci., 14 (1981), 353.

(14) K. Nogi and K. Ogino: J. Japan Inst. Metals, 52 (1988), 786.

(15) A. A. Berg: J. Electrochem. Soc., 110 (1963), 908.

(16) B. Goldstein: RCA Rev., 18 (1959), 213.

(17) O. Kubaschewski and C. B. Alcock: METALLURGICAL THERMOCHEMISTRY, International Series on Materials Science and Technology, Pergamon Press, Oxford, New York, Toronto, Sydney, Paris, Frankfurt, Vol. 24 (1979). 